\title{
Use of Amoxicillin-Clavulanate and Resistance in ESCHERICHIA COLI OVER A 4-YeAR PERIOD
}

\author{
Stephanie Natsch, PhD; Christian Conrad, ICP; Cora Hartmeier, PhD; Beat Schmid, PhD
}

\begin{abstract}
OBJECTIVE: To reduce the use of amoxicillin-clavulanate after high-resistance rates in Escherichia coli were detected.

DESIGN: Intervention study; the interventions were introduced successively over a 4-year period while closely monitoring the resistance patterns.

SETTING: A 260-bed acute-care hospital in Switzerland.

INTERVENTIONS: Introduction of therapeutic guidelines for specific departments or indications, which proposed alternative antibiotics to amoxicillin-clavulanate. The perioperative prophylactic use of amoxicillin-clavulanate was eliminated completely.

RESULTS: The absolute amount of amoxicillin-clavulanate consumed decreased by $23 \%$, from $24.8 \mathrm{~g}$ per 100 patient days in 1992 to $18.5 \mathrm{~g}$ per 100 patient days in 1995 . The number of courses, a parameter that takes the prophylactic use into account, decreased by $62 \%$ from 2.3 per 100 patient days in 1992 to 0.9 per

100 patient days in 1995 . The percentage of sensitive strains increased from 54.9\% ( $\mathrm{n}=512)$ in 1992 and $54.0 \%(\mathrm{n}=506)$ in 1993 to $72.1 \%(n=546)$ in 1994 and $83.1 \%(n=668)$ in 1995. No major changes were detected for other antimicrobials, such as cotrimoxazole, tetracycline, or cefuroxime, used in this 4-year period.

CONCLUSIONS: A decrease in the use of amoxicillinclavulanate was followed by an increase in susceptibility of $E$ coli to it. It was not possible to prove a causative relationship. Only a temporal association was discovered. The reduction of the use of amoxicillin-clavulanate was achieved through the implementation of treatment guidelines, facilitated through a close collaboration among the clinical pharmacists, the infection control practitioner, the microbiology laboratory, and the physicians in charge of the respective departments (Infect Control Hosp Epidemiol 1998;19:653-656)
\end{abstract}

Several articles have been published that show a connection between the use of antimicrobials and the development of resistance. In 1979, Buckwold and Ronald ${ }^{1}$ discussed this issue and proposed improved medical education, the adaptation of a policy restricting the use of specific antimicrobial agents, the introduction of guidelines, and a close collaboration among hospital infection and pharmacy committees and the clinical microbiology laboratories. Hollmann ${ }^{2}$ analyzed data on antimicrobial consumption and resistance patterns in 1980 and discovered a correlation. In 1983, Daschner et al ${ }^{3}$ stated that the restriction of the use of antimicrobials often leads to a decrease in resistance rates. In 1983, McGowan ${ }^{4}$ compiled a review of studies performed from 1950 to 1980, which showed a relation between antibiotic use and resistance. In 1987, he assumed that epidemiological criteria for a causal relationship between antibiotic use and resistance of hospital organisms was supported by new data despite confounding variables inherent in the studies. ${ }^{5}$ In 1994 , McGowan stated that the temporal association between resistance and use already asked for the development of appropriate measures such as education of prescribers, the implementation of restrictions, and intensive control programs. ${ }^{6}$ Several authors published data that compared specific antimicrobials with specific species of bacteria. Ma et al reported a substantial decrease in cephalosporin resistance in gram-negative bacilli after a marked decrease in prescribing of these drugs. ${ }^{7}$ Data on antibiotic purchases and bacterial susceptibilities in 18 hospitals in the United States revealed a statistically significant correlation between increasing ceftazidime use and increasing Enterobacter cloacae resistance. ${ }^{8}$ Richard et al reported the results of a case-control study and found that treatment with fluoroquinolones was an independent risk factor for nosocomial infections caused by fluoroquinolone-resistant gram-negative bacilli. ${ }^{9}$

Sanders and Sanders ${ }^{10}$ published a review of resistance to $\beta$-lactam antibiotics in gram-negative rods. There are several possible factors determining resistance to amoxicillin-clavulanate in Escherichia coli. One is TEM-1 ß-lactamase hyperproduction. ${ }^{11-13}$ Another mechanism of resistance may be an altered permeability of the outer cell membrane. ${ }^{14}$ Others described mutations in the genes encoding for TEM-1 $\beta$-lactamases. ${ }^{15-17}$ Published data on the rate of resistance to amoxicillin-clavulanate in $E$ coli vary considerably. In France, isolates from urine in 1993 showed 25\% of strains were resistant, and $15 \%$ were intermediate. ${ }^{11}$ On the other hand, a survey of isolates from six intensive-care units in Switzerland in 1994 showed $93 \%$ of strains were sensitive. ${ }^{18}$ Kastanakis et al from Crete reported that $18 \%$

From the Clinical Pharmacy (Dr. Natsch); the Department of Infection Control (Mr. Conrad); the Hospital Pharmacy (Dr. Hartmeier); and the Department of Pharmacy and Laboratory (Dr. Schmid), Hospital of Schaffhausen, Switzerland.

These results were partially presented as a poster at the annual meeting of the Swiss Society for Infectiology in Zürich in 1996.

Address reprint requests to B. Schmid, PhD, Hospital Pharmacy, Hospital of Schaffhausen, CH-8208 Schauffhausen, Switzerland.

96-OA-231. Natsch S, Conrad C, Hartmeier C, Schmid B. Use of amoxicillin-clavulanate and resistance in Escherichia coli over a 4-year period. Infect Control Hosp Epidemiol 1998;19:653-656. 
of strains in urine and $30 \%$ of strains from other sources were resistant, ${ }^{19}$ whereas Kouppari et al ${ }^{20}$ reported less than $2 \%$ of strains isolated from neonates in the Children's Hospital in Athens were resistant.

\section{METHODS}

\section{Setting}

The present study was conducted at a 260-bed acutecare hospital in Schaffhausen, Switzerland. The data from the four major departments (surgery, internal medicine, obstetrics-gynecology, and the interdisciplinary intensivecare unit) have been analyzed, amounting to approximately 65,000 to 70,000 patient days per year.

\section{Antibiotic Consumption}

The hospital pharmacy's annual analysis of the amount of antimicrobials delivered to all of the departments in the hospital has been calculated in two different ways:

1. In gram of substance; this parameter showed the total amount of the drugs used in the hospital.

2. In number of courses; this parameter indicated how many times the decision to use amoxicillin-clavulanate was made. This was of particular interest because the interventions taken concerned the prophylactic use of the drug, as well as the dosages. The following assumptions have been made: (1) the quantities of prophylactic courses were known from a survey of all surgical patients in 1993 and from the number of hysterectomies and cesarean sections performed in the hospital; (2) for therapeutic use, an average duration of treatment of 7 days has been assumed for the ward and 3 days for the intensive-care unit (according to the average length of stay in that unit).

\section{Surveillance of Resistance}

Data from routine resistance testing in the microbiology laboratory were analyzed using a computer program (ResiMed, written by M. L. Mueller and C. Conrad ${ }^{21}$ ). The system eliminated duplicate specimens if the isolates came from the same patient in the same material and with the same resistance pattern. The fact that isolates from multiple sites from the same patient are included in the analysis did not have any influence on the results.

Routine resistance testing was performed by the disc diffusion method ${ }^{22}$ using culture media from Bio-Life (Milan, Italy) and antibiotic discs from Becton-Dickinson-Europe (Meylan, France).

\section{Control of the Resistance Testing}

Between November 1994 and February 1995, 30 consecutive isolates determined by routine testing to be intermediately sensitive to amoxicillin-clavulanate were collected. Their susceptibility was tested again using materials from different manufacturers. For the disc diffusion method, ${ }^{22}$ antibiotic discs from Becton-Dickinson, as well as from Sanofi (Sanofi Diagnostics Pasteur, Marnes La Coquette, France) were used. To determine the minimum inhibitory

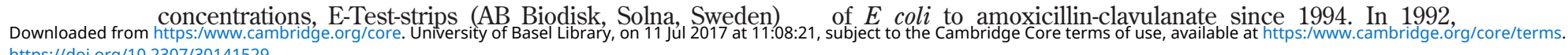
https://doi.org/10.2307/30141529 were used. Both methods were performed on culture media from Bio-Life, as well as from Sanofi. The interpretation of the results was made according to the guidelines of the National Committee for Clinical Laboratory Standards. ${ }^{22}$

To influence the use of amoxicillin-clavulanate, the following interventions were undertaken:

- In the guidelines for the prophylactic and therapeutic use of antimicrobials in the department of gynecology and obstetrics, implemented at the beginning of 1993, the use of amoxicillin-clavulanate was abandoned completely. For prophylaxis, amoxicillin was substituted alone, because these patients usually come directly from home and are not expected to carry nosocomial pathogens. For treatment, cefuroxime was introduced instead.

- In the guidelines for treatment of urinary tract infections, introduced in all departments in October 1994, cefuroxime replaced amoxicillin-clavulanate for the indications "pyelonephritis" and "urosepsis."

- In the guidelines for perioperative antimicrobial prophylaxis in the department of surgery, introduced at the beginning of 1995, amoxicillin-clavulanate was replaced by cefoxitin.

- For the treatment of infections caused by Staphylococcus aureus and for soft-tissue infections, it was proposed that flucloxacillin be used whenever possible.

- Furthermore, it was advised that amoxicillin-clavulanate be used in a very restricted manner in the intensivecare unit.

All of these changes were made in close interdisciplinary collaboration among the physicians, the clinical pharmacist, and the infection control practitioner and on the basis of comprehensive surveillance data. The implementations consisted of oral presentations of the new guidelines, information for all prescribing physicians, and the introduction of the guidelines in the handbooks of the departments. Beginning in 1993, all physicians new at the hospital were trained by the infection control practitioner and the clinical pharmacist about the local situation concerning resistance problems and guidelines for use. Additionally, a consultation service running during working hours and daily ward rounds of the infection control practitioner and the clinical pharmacist were implemented.

\section{RESULTS}

\section{Use of Amoxicillin-Clavulanate}

The total amount of amoxicillin-clavulanate used decreased over the period of 4 years by $23 \%$, from $24.8 \mathrm{~g}$ per 100 patient days in 1992 to $18.5 \mathrm{~g}$ per 100 patient days in 1995. The number of courses over the same period dropped by almost $62 \%$, from 2.3 per 100 patient days in 1992 to 0.9 per 100 patient days in 1995. Detailed data are shown in Table 1.

\section{Development of Resistance}

There was a continuous increase in the susceptibility

of $E$ coli to amoxicillin-clavulanate since 1994. In 1992 of $E$, coli to amoxicillin-clavulanate since 1994 . In 1992, ame

\section{Interventions}


TABLE 1

Consumption of Amoxicillin-Clavulanate by Service and Year

\begin{tabular}{|c|c|c|c|c|c|c|c|c|c|c|}
\hline \multirow[b]{3}{*}{ Year } & \multicolumn{10}{|c|}{ Use per 100 Patient Days } \\
\hline & \multicolumn{2}{|c|}{ Surgery } & \multicolumn{2}{|c|}{$\begin{array}{l}\text { Internal } \\
\text { Medicine }\end{array}$} & \multicolumn{2}{|c|}{$\begin{array}{l}\text { Obstetrics- } \\
\text { Gynecology }\end{array}$} & \multicolumn{2}{|c|}{$\begin{array}{l}\text { Intensive- } \\
\text { Care Unit }\end{array}$} & \multicolumn{2}{|c|}{ Total } \\
\hline & Grams & Courses & Grams & Courses & Grams & Courses & Grams & Courses & Grams & Courses \\
\hline 1992 & 22.0 & 2.4 & 23.3 & 1.4 & 23.7 & 3.6 & 98.8 & 6.8 & 24.8 & 2.3 \\
\hline 1994 & 19.9 & 2.0 & 21.5 & 1.0 & 1.1 & 0.1 & 53.3 & 3.0 & 18.2 & 1.3 \\
\hline 1995 & 17.3 & 0.8 & 24.2 & 1.1 & 2.7 & 0.2 & 52.7 & 3.3 & 18.5 & 0.9 \\
\hline 1995 vs 1992 & $-21.4 \%$ & $-65.5 \%$ & $+3.8 \%$ & $-24.3 \%$ & $-88.6 \%$ & $-95.2 \%$ & $-46.6 \%$ & $-51.3 \%$ & $-23.0 \%$ & $-61.8 \%$ \\
\hline
\end{tabular}

TABLE 2

Resistance in EsCherichia coli to Amoxicillin-Clavulanate by Service and Year

\begin{tabular}{|c|c|c|c|c|c|c|c|c|c|c|c|c|c|c|c|}
\hline \multirow[b]{3}{*}{ Year } & \multicolumn{15}{|c|}{ Percentage of Strains Categorized as (R)esistant, (I)ntermediate, and (S)ensitive } \\
\hline & \multicolumn{3}{|c|}{ Surgery } & \multicolumn{3}{|c|}{$\begin{array}{c}\text { Internal } \\
\text { Medicine }\end{array}$} & \multicolumn{3}{|c|}{$\begin{array}{l}\text { Obstetrics- } \\
\text { Gynecology }\end{array}$} & \multicolumn{3}{|c|}{$\begin{array}{l}\text { Intensive- } \\
\text { Care Unit }\end{array}$} & \multicolumn{3}{|c|}{ Total } \\
\hline & $\overline{\mathbf{R}}$ & $\mathbf{I}$ & $\mathbf{s}$ & $\mathbf{R}$ & $\mathbf{I}$ & $\mathbf{s}$ & $\mathbf{R}$ & $\mathbf{I}$ & $\mathbf{s}$ & $\mathbf{R}$ & $\mathbf{I}$ & $\mathbf{s}$ & $\mathbf{R}$ & $\mathbf{I}$ & $\mathbf{s}$ \\
\hline 1992 & 32.4 & 23.4 & 44.2 & 14.7 & 30.7 & 54.6 & 6.8 & 39.0 & 54.2 & 34.9 & 30.2 & 34.9 & 17.2 & 27.9 & 54.9 \\
\hline 1993 & 23.0 & 21.2 & 55.8 & 16.7 & 31.0 & 52.3 & 14.5 & 36.1 & 49.4 & 29.3 & 27.6 & 43.1 & 16.8 & 29.2 & 54.0 \\
\hline 1994 & 24.7 & 25.3 & 50.0 & 2.9 & 21.4 & 75.7 & 0 & 17.0 & 83.0 & 36.2 & 24.6 & 39.1 & 9.2 & 18.7 & 72.1 \\
\hline 1995 & 5.1 & 11.3 & 83.6 & 7.9 & 13.0 & 79.1 & 7.7 & 13.9 & 78.4 & 6.3 & 12.5 & 81.3 & 5.7 & 11.2 & 83.1 \\
\hline
\end{tabular}

$54.9 \%$ of the 512 strains isolated were sensitive, and in 1993 , $54 \%$ of 506 strains were sensitive. But this percentage increased in 1994 to $72.1 \%$ ( $\mathrm{n}=546)$, and in 1995 to $83.1 \%$ $(\mathrm{n}=668)$. Surprisingly, in 1992 a high percentage of intermediate strains were isolated, $27.9 \%$, which decreased to $11.2 \%$ in 1995 . In $1992,17.2 \%$ of strains were resistant, and this figure decreased to $5.7 \%$ in 1995 . The detailed data are summarized in Table 2.

\section{Use and Resistance of Other Antimicrobials}

Three other antimicrobials used over the 4-year period from 1992 to 1995 were evaluated: cotrimoxazole, tetracycline, and cefuroxime. No major changes in susceptibility could be detected. The susceptibility of $E$ coli remained stable to cotrimoxazole and tetracycline with $80.7 \%$ to $87.6 \%$ and $68.3 \%$ to $75.7 \%$, respectively, and even increased to cefuroxime from $87.4 \%$ to $96.8 \%$. The amount of the drug used varied for cotrimoxazole, doubled for tetracycline, and increased 10-fold for cefuroxime (Table 3).

The use of broad-spectrum antimicrobials increased from 1992 to 1995, but no changes were detected in the resistance pattern of $E$ coli. Because these substances were not in use during the entire 4-year period, the data are not shown in detail.

\section{Validation of the Routine Resistance Testing}

Control assays of intermediate strains from the routing testing yielded homogeneous results. For the agar disc diffusion tests, the diameters measured lay between 11 and $21 \mathrm{~mm}$ and their averages between 14.5 and $16.6 \mathrm{~mm}$, $21 \mathrm{~mm}$ and their averages between 14.5 and $16.6 \mathrm{~mm}$, cillin-clavulanate was followed by an increase in suscepti-

TABLE 3

Consumption and Resistance Patterns of Other Antimicrobials From 1992 to 1995 (All Departments)

Use in Grams per 100 Patient Days (\% Sensitive)

\begin{tabular}{lccccc}
\hline Antibiotic & $\mathbf{1 9 9 2}$ & $\mathbf{1 9 9 3}$ & $\mathbf{1 9 9 4}$ & $\mathbf{1 9 9 5}$ \\
\hline Cotrimoxazole & $4.8(86.1)$ & $10.5(87.6)$ & $5.4(80.7)$ & $3.3(84.1)$ \\
Tetracycline & $0.0(71.4)$ & $0.1(68.3)$ & $0.1(69.5)$ & $0.1(75.7)$ \\
Cefuroxime & $0.4(87.4)$ & $0.8(94.6)$ & $0.9(95.4)$ & $3.7(96.8)$ \\
\hline
\end{tabular}

depending on the materials used. Determination of the minimum inhibitory concentration by E-test resulted in values from 4 to $16 \mu \mathrm{g} / \mathrm{mL}$, with averages between 10.3 and 11.8 $\mu \mathrm{g} / \mathrm{mL}$. The different test media yielded the same results.

\section{Cross-Resistance}

E coli strains with decreased susceptibility to amoxicillin-clavulanate also had decreased susceptibility to firstgeneration cephalosporins, cotrimoxazole, and tetracycline, and, to a lesser extent, to second- and third-generation cephalosporins (Table 4). There were only a few strains intermediately sensitive or resistant to tobramycin, imipenem, or piperacillin-tazobactam.

\section{DISCUSSION}

In the present study, a decrease in the use of amoxicillin-clavulanate was followed by an increase in suscepti-
21 , subject to the cambridge core terms of use, available at https:/www.cambridge.org/core/terms. 
TABLE 4

Cross-Resistance in ESCHERICHIA COLI IN 1992 AND IN 1995, IsOlates OF All DePARTMENTS

\begin{tabular}{|c|c|c|c|c|c|c|}
\hline \multirow[b]{2}{*}{ Resistant to: } & \multicolumn{3}{|c|}{1992} & \multicolumn{3}{|c|}{1995} \\
\hline & $\begin{array}{c}\text { AMC- } \\
\text { Sensitive }\end{array}$ & $\begin{array}{c}\text { AMC- } \\
\text { Intermediate }\end{array}$ & $\begin{array}{c}\text { AMC- } \\
\text { Resistant }\end{array}$ & $\begin{array}{c}\text { AMC- } \\
\text { Sensitive }\end{array}$ & $\begin{array}{c}\text { AMC- } \\
\text { Intermediate }\end{array}$ & $\begin{array}{c}\text { AMC- } \\
\text { Resistant }\end{array}$ \\
\hline Ceph-1 & $61.2 \%$ & $97.9 \%$ & $95.3 \%$ & $20.7 \%$ & $85.3 \%$ & $79.0 \%$ \\
\hline Ceph-2 & $0 \%$ & $3.4 \%$ & $24.7 \%$ & $1.2 \%$ & $8.0 \%$ & $21.1 \%$ \\
\hline Ceph-3 & $0 \%$ & $0 \%$ & $4.7 \%$ & $0.2 \%$ & $0 \%$ & $2.6 \%$ \\
\hline Tetracycline & $18.3 \%$ & $41.2 \%$ & $56.4 \%$ & $18.1 \%$ & $54.6 \%$ & $52.7 \%$ \\
\hline Cotrimoxazole & $2.9 \%$ & $21.0 \%$ & $27.1 \%$ & $10.9 \%$ & $38.6 \%$ & $44.7 \%$ \\
\hline
\end{tabular}

Abbreviations: AMC, amoxicillin-clavulanate; ceph-1, first-generation cephalosporin; ceph-2, second-generation cephalosporin; ceph-3, third-generation cephalosporin.

bility of $E$ coli to it. The reduction in amoxicillin-clavulanate use was achieved mainly through the introduction of treatment guidelines into daily clinical practice, in which alternative antibiotics were suggested whenever possible.

It is not possible to show a causative relationship between these two parameters, but there was a clear temporal association between antibiotic-use restriction and resistance patterns.

During the study period, a dramatic increase in the use of cefuroxime occurred. Thus far, this has not had any adverse effect on resistance rates. However, use and susceptibility must be monitored closely in the future, because follow-up monitoring of the present study was short, with only 4 years' worth of data.

The high percentage of intermediate strains in $E$ coli raised doubts as to the appropriateness of the routine testing. However, control tests performed with materials from different manufacturers yielded the same results and thus confirmed the data.

The mechanism of resistance was not proven, but analysis of the pattern of cross-resistance could imply that the cause of resistance may be overproduction of TEM-1 $\beta$ lactamases, as described in the introduction.

An important aspect of the present study was that all actions were taken in close collaboration with the clinical pharmacists, the infection control practitioner, the microbiology laboratory, and the physicians in charge of the respective departments. This interdisciplinary approach facilitated the implementation of the necessary measures. Ongoing surveillance of the development of resistance, as well as the use of antibiotics in a specific setting, are an important procedural basis from which to detect any adverse events as soon as possible and to take appropriate measures. This procedure will allow control over, and will restrict the use of, antibiotics, as well as the development of resistance.

\section{REFERENCES}

1. Buckwold FJ, Ronald AR. Antimicrobial misuse-effects and suggestions for control. J Antimicrob Chemother 1979;5:129-136.

2. Hollmann M. Chemotherapeutic-bacteriological interdependences observed by use of a clinical anti-infective drug monitoring system. Eur J Clin Pharmacol 1980;17:101-109.

3. Daschner F, Langmaack H, Wiedemann B. Antibiotic resistance in intensive care unit areas. Infect Control 1983;4:382-387.
4. McGowan JE Jr. Antimicrobial resistance in hospital organisms and its relation to antibiotic use. Rev Infect Dis 1983;5:1033-1048.

5. McGowan JE Jr. Is antimicrobial resistance in hospital microorganisms related to antibiotic use? Bull NY Acad Med 1987;63:253-268.

6. McGowan JE Jr. Do intensive hospital antibiotic control programs prevent the spread of antibiotic resistance? Infect Control Hosp Epidemiol 1994;15:478-483.

7. Ma MY, Goldstein EJ, Friedman MH, Anderson MS, Mulligan ME. Resistance of gram-negative bacilli as related to hospital use of antimicrobial agents. Antimicrob Agents Chemother 1983;24:347-352.

8. Ballow CH, Schentag JJ. Trends in antibiotic utilization and bacterial resistance. Report of the national nosocomial resistance surveillance group. Diagn Microbiol Infect Dis 1992;15:37S-42S.

9. Richard P, Delangle MH, Merrien D, Barille S, Reynaud A, Minozzi C, et al. Fluoroquinolone use and fluoroquinolone resistance: is there an association? Clin Infect Dis 1994;19:54-59.

10. Sanders CC, Sanders WE Jr. Beta-lactam resistance in gram-negative bacteria: global trends and clinical impact. Clin Infect Dis 1992;15:824839.

11. Henquell C, Sirot D, Chanal C, De Champs C, Chatron P, Lafeuille B, et al. Frequency of inhibitor-resistant TEM $\beta$-lactamases in $E$ coli isolates from urinary tract infections in France. J Antimicrob Chemother 1994;34:707-714.

12. Wu PJ, Shannon K, Phillips I. Effect of hyperproduction of TEM-1 betalactamase on in vitro susceptibility of $E$ coli to beta-lactam antibiotics. Antimicrob Agents Chemother 1994;38:494-498.

13. Martinez JL, Cercenado E, Rodriguez-Creixems M, Vincente-Perez MF, Delgado-Iribarren A, Baquero F. Resistance to beta-lactam-clavulanate. Lancet 1987;2:1473.

14. Reguera JA, Baquero F, Pérez-Diaz JC, Martinez JL: Factors determining resistance to $\beta$-lactam combined with $\beta$-lactamase inhibitors in $E$ coli. J Antimicrob Chemother 1991;27:569-575.

15. Sirot D, Chanal C, Henquell C, Labia R, Sirot J, Cluzel R. Clinical isolates of $E$ coli producing multiple TEM mutants resistant to beta-lactamase inhibitors. J Antimicrob Chemother 1994;33:1117-1126.

16. Zhou XY, Bordon F, Sirot D, Kitzis MD, Gutmann L. Emergence of clinical isolates of $E$ col $i$ producing TEM-1 derivatives or an oxa-1 beta-lactamase conferring resistance to beta-lactamase inhibitors. Antimicrob Agents Chemother 1994;38:1085-1089.

17. Blazquez J, Baquero MR, Canton R, Alos I, Baquero F. Characterization of a new TEM-type beta-lactamase resistant to clavulanate, sulbactam, and tazobactam in a clinical isolate of $E$ coli. Antimicrob Agents Chemother 1993;37:2059-2063.

18. Wust J, Auckenthaler R, Breer C, Frei R, Heinzer I, Kamm W. Antibiotika-Empfindlichkeit von gramnegativen Bakterien auf Intensivpflegestationen in der Schweiz. Schweiz Med Wochenschr 1994;124:1695-1700.

19. Kastanakis S, Tzimis L, Papadomanolaki E, Alevraki G, Tsouri A, Koutsouba D, et al. Resistance patterns of $E$ coli in a general hospital on the island of Crete. Medical Microbiology Letters 1996;5:S79.

20. Kouppari G, Zaphiropoulou A, Tsirepa M, Xenos N, Deliyianni V, Dellagrammaticas $\mathrm{H}$. Resistance of $E$ coli isolated from neonates. Medical Microbiology Letters 1996;5:S83.

21. Mueller ML, Conrad C, Schmid B. Epidemiologische Datenanalyse im Krankenhaus: Einsatz eines online-computer systems zur automatisierten Erreger- und Resistenzstatistik. Krh.-Hyg. + Inf.verh. 1997;19:43-47.

22. Barry AL, Thornsberry C: Susceptibility tests: diffusion test procedures. In: Balows A, Hausler WJ, Herrmann KL, Isenberg HD, Shadomy HJ, eds. Manual of Clinical Microbiology. Washington, DC, American Society for Microbiology; 1991:1117-1125. 